\title{
Experimental and FE analysis of void closure in hot rolling of stainless steel
}

\author{
Faini F*, Attanasio A., Ceretti E. \\ University of Brescia, Department of Mechanical and Industrial Engineering, Via Branze 38, 25123 Brescia, Italy
}

\section{A R T I C L E I N F O}

\section{Keywords:}

Hot rolling

Finite element method (FEM)

Void closure

Geometrical indexes

AISI 316L

\begin{abstract}
A B S T R A C T
Casting metal products are characterized by undesired void defects due to the shrinkage occurring during the solidification of molten material. In order to deliver safe and sound components satisfying the customer requirements, these defects need to be reduced or if possible eliminated. Hot metal forming processes can be used for this purpose therefore, the calibration of their parameters is a fundamental task. In this paper a study of the void closure during hot rolling of 316L stainless steel slabs coming from continuous casting has been conducted. The effects of the hot rolling main parameters (i.e. percentage of reduction, cooling time, and side of reduction) on void closure index have been investigated by means of FE analysis. Data coming from experimental tests performed by Cogne Acciai Speciali S.p.a. were utilised to validate the model and the research results. A correlation between void closure indexes and the residual voids along the hot rolled slabs axis was found for AISI 316L stainless steel. Moreover, new geometric indexes depending on the rolling parameters were defined. Also in this case a correlation between these new indexes and the void closure was found.
\end{abstract}

\section{Introduction}

Continuous or ingot casting processes produce parts affected by voids because of the shrinkage occurring during the metal solidification. These defects are irregular in shape and size and their location within the material depends on the casting conditions. Generally, these defects are mainly located along the longitudinal axis of the part as shown in Fig. 1.

Hot metal forming processes (such as rolling, forging, and cogging) are usually utilised to reduce, or when possible to close, these voids. Consequently, the choice of the best process and of its working parameters is an important issue.

In the literature, several studies were developed with the aim of analysing the influence of hot metal forming processes on void closure. Stahlberg et al. (1980) analysed the void closure of artificial voids in plane strain forging with parallel dies and they proposed a theoretical model of the phenomenon relating the void closure with the reduction ratio. Banaszek and Stefanik (2006) studied the void closure in forging by means of experimental and FEM analyses. They identified an objective function based on reduction ratio, die speed and material temperature able to find the best set of process parameters minimising the void dimensions. The review paper of Llanos et al. (2008) summarises the results of some researches focused on studying the effect of rolling process parameters on internal voids. By means of experimental and numerical simulation Hwang and Hwang and Chen, 2003 investigated the effect on void closure of reduction ratio, dimension of the internal void, friction factor, and cross-sectional area of the void. They found a value of critical reduction at which the voids are completely closed. Wallerö, 1985 found that during hot rolling the dimension of central voids decreases when reduction ratio is increased by using larger rolls and larger spread. These results are in agreement with the researches of Stahlberg (1986), who showed that large spread plays a positive role in void closure. Chen, 2006 studied the void closure during rolling of porous metal sheets concluding that the relative density of porous material increases (i.e. the dimension of voids decreases) as the reduction ratio, the friction factor and the roll diameter increase. Other studies were focused on the effect of the temperature gradient in the workpiece. In fact, by means of experimental tests Stahlberg and Keife (1992) found that during hot rolling a high temperature gradient in the part, obtained by water cooling, improves the voids reduction. These results are in agreement with the data reported by Lllanos et al. (2008).

From the literature analysis it is possible to conclude that the best effects on void closure are due to thermal gradient between skin and core of the workpiece, to large single pass reduction, to larger rolls diameters, larger spread and friction between slab and rolls.

Once identified the main process parameters affecting the void closure, the definition of a procedure able to predict the void evolution during metal forming processes is fundamental. As reported in the review paper of Saby et al. (2015a) different approaches can be adopted to develop a void closure model. The choice of the suitable approach is related to the utilized strategy (i.e. analytical, numerical, empirical or their combinations) and to the dimensional scale at which the void

\footnotetext{
* Corresponding author

E-mail address: f.faini001@unibs.it (F. Faini).
} 


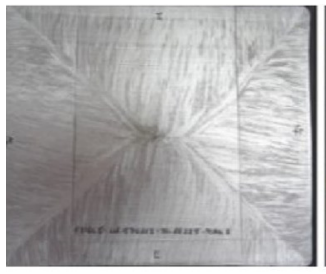

a)

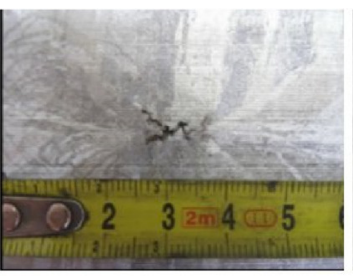

b)

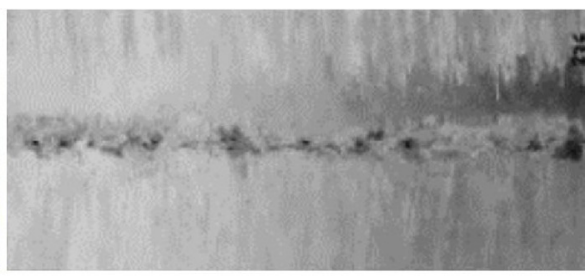

c)

Fig. 1. a) Transversal section of an AISI 316L billet. b) Detail of the central transversal section defect. c) Longitudinal section.

closure is investigated (macroscopic or microscopic scale). The macroscopic or process approaches usually analyse the problem at macro scale with the support of FE software. The FE model can implement internal voids (explicit macroscopic approaches) or not. These approaches are easy to be implemented and allow to identify the influence of the process parameters on void closure at macro scale. On the other hand, it is hard to generalise them since they can represent just a specific forming process. Differently, the approaches performed at micro scale (micro analytical approaches) study the problem from a micromechanical point of view, considering a single void in an infinite matrix. They are difficult to implement and typically they are not able to take into account the change of void shape during deformation. Moreover, the results coming from these approaches are not suitable for industrial applications. Saby et al. (2013) combined these two family of approaches studying the problem at meso scale with the support of FE analysis. In this research a three dimensional Representative Volume Element (RVE) was defined to perform simulations at the micro scale. The mechanical boundary conditions to be applied to the RVE were derived from macroscopic FE simulations of a forming process. The neural networks were used to develop void closure models too. Chen et al., 2011 studied the closure of cylindrical and spheroidal voids in cold flat rolling of Aluminium alloys. Experimental tests and FEM simulations were used to train and validate a void closure neural network model. This model was found accurate and faster than FEA in terms of computational time.

These combined approaches can monitor the void evolution just by means of a closure criterion. Several studies utilised mechanical indexes as closure criterion. Saby et al. (2015a) define one of the most common index to represent void closure: the stress triaxiality ratio $\left(T_{X}\right)$ defined as the ratio between the hydrostatic pressure $\left(\sigma_{h}\right)$ and the Von Mises equivalent stress $\left(\sigma_{e q}\right)$, as reported in Eq. (1).

$T_{X}=\frac{\sigma_{h}}{\sigma_{e q}}=\frac{\sigma_{x}+\sigma_{y}+\sigma_{z}}{3 \cdot \sigma_{e q}}$

Tanaka et al. (1986) considered as index to predict void closure the integral $(Q)$ over the cumulated Von Mises equivalent strain $\varepsilon_{e q}$ of $T_{X}$ (Eq. (2)).

$Q=\int_{0}^{\varepsilon_{e q}} T_{X} d \varepsilon_{e q}$

Nakasaki et al. (2006) developed FEM models able to estimate the distribution of $Q$ in forged and hot rolled samples, concluding that a complete void closure can be reached when $Q$ is lower than -0.18 . Kakimoto et al. (2010) investigated by means of FE analysis the effect of the shape and position of the void in the billet during hot compression of aluminium samples. In this case the void closure is obtained for values of $Q$ lower than -0.21 . Kang et al. (2010) proposed a void closure model based on the evaluation of the $Q$ index over the surface of the void which presents compressive hydrostatic stresses. Chen and Lin, 2013 studied the evolution of the void in the space proposing a three dimensional void closure model based on the estimation of three different values of $Q$, one for each direction ( $\mathrm{x}, \mathrm{y}$ and $\mathrm{z}$ ). Other mechanical indexes were proposed in addition to $T_{X}$ or $Q$. Saby et al (2015b) developed a void closure model starting from RVE simulations performed by using ellipsoidal voids under different orientation with respect to the loading direction. Recently Chbihi et al. (2017) proposed a new version of the Saby model introducing the influence of the Lode angle $\theta$.

Instead of mechanical indexes Farrugia (2016) suggested geometric process indexes as closure criterion. These indexes, correlated to the mechanical ones, are calculated considering the process parameters such as the reduction ratio, the mean height of the workpiece, the length of contact and so on.

Despite the wide literature concerning void closure in casting products, there is a lack of information on void closure of stainless steel. This research aims to fill this lack studying the effect of hot rolling parameters on the reduction of voids on AISI 316L slabs. A process scale approach was applied for identifying the main mechanical indexes that drive the void closure. In particular, the influence of the integral of $T_{X}$ $(Q)$ and the equivalent deformation $\left(\varepsilon_{\mathrm{eq}}\right)$ on void closure $\mathrm{w}$ investigated. To validate a FE model of hot rolling industrial experimental tests were performed by Cogne Acciai Speciali S.p.a.. Being the dimension of the voids much lower than workpiece dimension as shown by Saby et al. 2013, a void free workpiece assumption was introduced in the developed FE model. In this way the relation between mechanical indexes and void closure was defined for AISI 316L stainless steel. After that, geometric indexes suitable for hot rolling were defined too.

\section{Experimental campaign}

Experimental tests were conducted by Cogne Acciai S.p.a. on twelve samples of AISI 316L. Each sample had a section of $280 \times 340 \mathrm{~mm}^{2}$ and a length of about $1000 \mathrm{~mm}$ and was cut from slabs obtained by continuous casting process. Table 1 provides the chemical composition of AISI 316L stainless steel.

Thin transversal sections of slabs were cut before rolling, in order to evaluate the dimension of the void along the longitudinal axis (Fig. 1). Rolling tests were performed on a Sack Pomini reversible duo mill with flat rolls (Fig. 2). Lower roll diameter was $985 \mathrm{~mm}$ while upper roll diameter was $980 \mathrm{~mm}$.

In this study the effects on void closure of thermal gradient, percentage of reduction and side of workpiece on which reduction is performed (shorter or longer side, as shown in Fig. 3) were investigated. In particular, thermal gradient in the workpiece was changed on two levels, obtained by cooling samples after the preheating furnace in air at room temperature $\left(20^{\circ} \mathrm{C}\right)$ respectively for $270 \mathrm{~s}$ and $180 \mathrm{~s}$. Furnace permanence was $12 \mathrm{~h}$ at $1250{ }^{\circ} \mathrm{C}$, in order to guarantee uniform heating in the samples at the target temperature.

The pass reduction was changed considering a percentage with

Table 1

Chemical composition of AISI 316L stainless steel.

\begin{tabular}{|c|c|c|c|c|c|c|c|c|c|}
\hline & $\mathrm{C} \% \leq$ & $\begin{array}{l}\mathrm{Mn} \\
\% \\
\leq\end{array}$ & $\mathrm{P} \% \leq$ & $\mathrm{S} \% \leq$ & $\mathrm{Si} \% \leq$ & $\begin{array}{l}\mathrm{Cr} \% \\
\leq\end{array}$ & $\mathrm{Ni} \% \leq$ & $\begin{array}{l}\text { Mo } \\
\% \\
\leq\end{array}$ & $\begin{array}{l}\text { Others } \\
\% \leq\end{array}$ \\
\hline AISI 316L & 0.03 & 2 & 0.045 & 0.015 & 1 & $\begin{array}{l}16.5 \\
- \\
18.5\end{array}$ & $10-13$ & $\begin{array}{l}2- \\
2.5\end{array}$ & $\begin{array}{l}\text { No } \\
\leq 0.11\end{array}$ \\
\hline
\end{tabular}




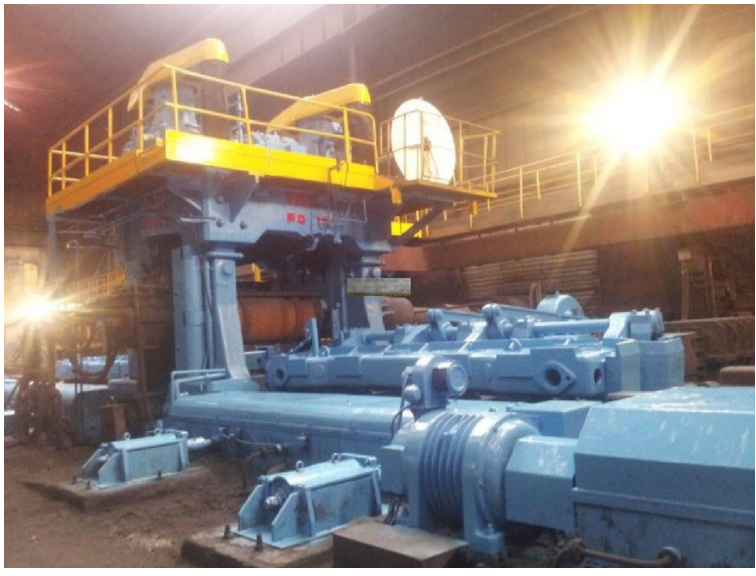

Fig. 2. The mill used in experimental tests.

respect to the initial height. Three level of pass reduction were considered, respectively equal to $14 \%, 21 \%$ and $28 \%$. Eq. (3) provides expression of percentage of reduction, where $h_{2}$ and $h_{1}$ are the height of workpiece after and before rolling respectively.

$\% R=\frac{h_{2}}{h_{1}} \cdot 100$

The side of reduction was varied assigning the above defined percentage reductions both on the short side $(280 \mathrm{~mm})$ and on the long side $(340 \mathrm{~mm})$ of the samples section.

Table 2 summaries the test parameters and values. The test code was chosen in order to make the identification of the process conditions easier. The first capital letter refers to the billet thermal gradient (i.e., A: thermal gradient after $270 \mathrm{~s}$ of cooling; B: thermal gradient after $180 \mathrm{~s}$ of cooling). The second capital letter refers to the side of reduction (i.e., S: reduction performed on short side; L: reduction performed on long side). The last number refers to the $\%$ pass reduction (i.e., 1 : percentage of reduction of $14 \%$; 2 : percentage of reduction of $21 \%$; 3 : percentage of reduction of $28 \%$; )

Rolls speed was unchanged. In particular, tests were performed with an angular velocity equal to $96 \mathrm{rpm}$ without lubrication.

\section{FEM campaign}

FE simulations were performed reproducing the conditions of each experimental test. For this purpose, FEM software Deform 3D v11 was employed. Workpiece was modelled as a void free plastic object and it was meshed with about 50,000 tetrahedral elements. Reference system was set as in Fig. 4, with the $\mathrm{x}$ axis coincident with rolling direction, $\mathrm{y}$ axis coincident with the transversal direction and $\mathrm{z}$ axis coincident with the reduction direction.

According to the experimental setup, in FE analysis samples temperature was initially set at $1250^{\circ} \mathrm{C}$, environment temperature was set at $20^{\circ} \mathrm{C}$ and a heat convection coefficient equal to $20 \mathrm{~W} /\left(\mathrm{m}^{2} \mathrm{~K}\right)$ was chosen in order to reproduce thermal gradient due to workpiece cooling time. The values of the AISI $316 \mathrm{~L}$ heat conductive coefficient as function of the temperature are reported in Table 3.

In order to model friction between rolls and workpiece, the shear friction model was utilised. This model supposes that the stresses due to friction may be a constant fraction of shear yield strength of the material as reported in Eq. (4).

$\tau_{i}=m \cdot k$

Where

- $\tau_{i}$ is the interface shear stress

- $m$ is the friction factor

- $k$ is the shear strength of the material

Since experimental tests were performed without lubrication, a shear friction factor equal to 0.7 was chosen in order to reproduce the high friction conditions between rolls and samples.

As far as AISI 316 L flow stress is concerned, due to the lack of experimental data at the temperature of interests, the thermo-viscoplastic behavior was described using the empirical model proposed by Hensel and Spittel, 1986. In particular, a reduced form of the model was employed as described by Eq. (5). Table 4 provides material coefficients of Eq. (5).

$\sigma_{e q}=A \cdot \exp \left(m_{1} \cdot T\right) \cdot \varepsilon_{e q}^{m_{2}} \cdot \exp \left(\frac{m_{4}}{\varepsilon_{e q}}\right) \cdot \dot{\varepsilon}_{e q}^{m_{3}}$

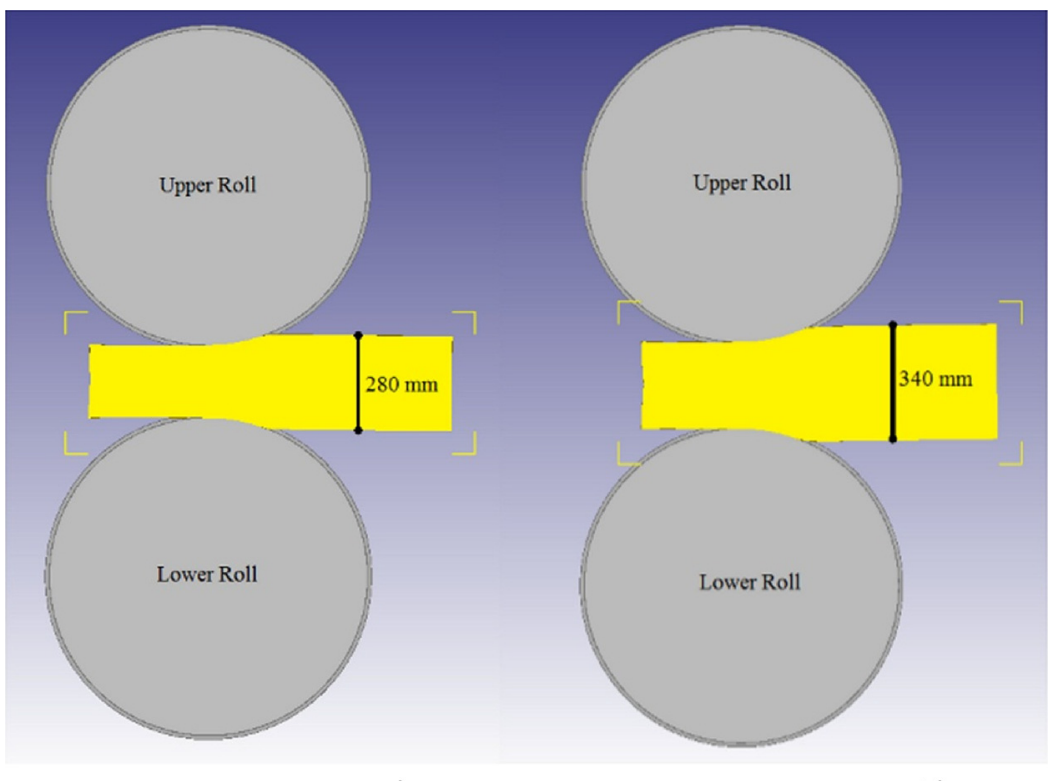

a)

b)

Fig. 3. a) Example of reduction performed on the short side. b) Example of reduction performed on the long side. 
Table 2

Experimental tests setup.

\begin{tabular}{|c|c|c|c|c|c|c|c|c|c|c|c|c|}
\hline Test code & AS1 & BS1 & AS2 & BS2 & AS3 & BS3 & AL1 & BL1 & AL2 & BL2 & AL3 & BL3 \\
\hline Time out of furnace [s] & 270 & 180 & 270 & 180 & 270 & 180 & 270 & 180 & 270 & 180 & 270 & 180 \\
\hline Side of reduction [mm] & 280 & 280 & 280 & 280 & 280 & 280 & 340 & 340 & 340 & 340 & 340 & 340 \\
\hline Reduction \% & 14 & 14 & 21 & 21 & 28 & 28 & 14 & 14 & 21 & 21 & 28 & 28 \\
\hline
\end{tabular}

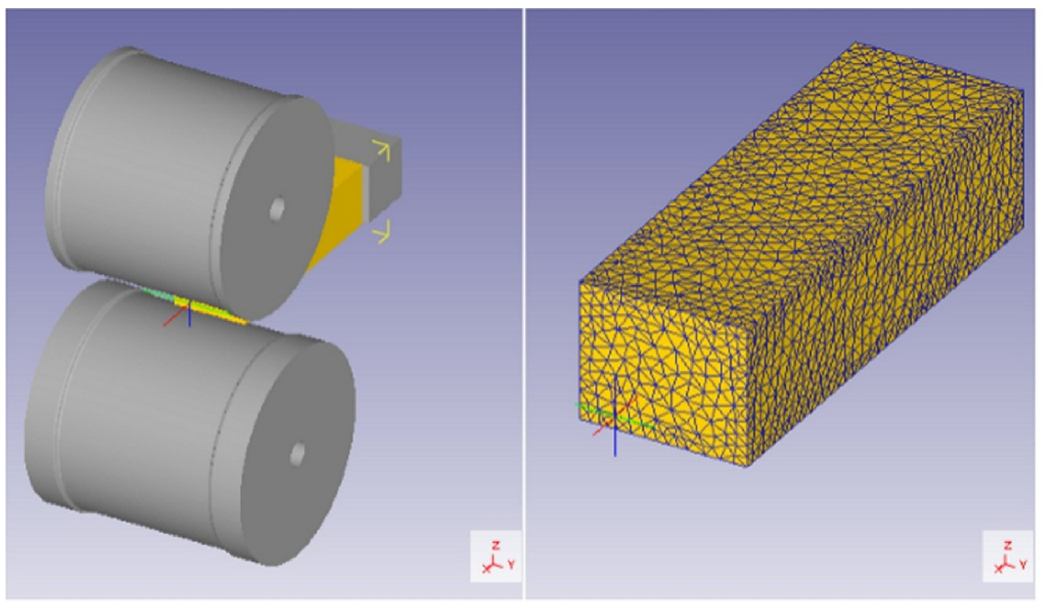

a)

b)

Fig. 4. a) The FEM model. b) Detail on the workpiece mesh.

Table 3

The heat conduction coefficient of AISI 316L as function of temperature used in FEA.

\begin{tabular}{ll}
\hline Temperature $\left[{ }^{\circ} \mathrm{C}\right]$ & Conductivity $\left[\mathrm{W} \mathrm{m}^{-1} \mathrm{~K}^{-1}\right]$ \\
\hline 20 & 14.36 \\
200 & 17.38 \\
400 & 20.28 \\
600 & 22.7 \\
800 & 24.68 \\
1000 & 26.1 \\
1200 & 27.08 \\
1400 & 27.58 \\
\hline
\end{tabular}

Table 4

The material coefficients of Hensel-Spittel flow stress model for AISI $316 \mathrm{~L}$ stainless steel used in FEA. The model used with the reported material coefficients returns the flow stress in terms of MPa.

\begin{tabular}{llllll}
\hline & A [MPa $]$ & $m_{1}\left[\mathrm{~K}^{-1}\right]$ & $m_{2}$ & $m_{3}$ & $m_{4}[\mathrm{~mm} / \mathrm{mm}]$ \\
\hline AISI 316L & 2745.39 & -0.0026 & 0.1127 & 0.1127 & -0.02
\end{tabular}

\section{Results and discussion}

\subsection{Experimental campaign results}

Ultrasound (US) controls were employed to measure the residual voids on samples after rolling. This technique was chosen because it is capable to quickly estimate void dimension and distribution in the samples. Moreover, it is a non-destructive control. In particular, US analysis provides the void dimension in terms of an equivalent flat bottom hole (FBH), the void position in the billet and the kind of distribution (continuum or isolated Fig. 5).

Equivalent FBH measurement was therefore adopted as a qualitative indicator of the actual void state in the samples. The main limitation of this technique is that no data about void geometry are provided. US analysis is also capable to give an estimation of the metal microstructure size in the samples, returning a percentage value of coarse structure detected. The higher this value the harder is the estimation of FBH from the US signal. Since only one single pass reduction on each sample was performed, a limited hot working recrystallization occurred. For this reason, a certain percentage of coarse structure remains in each samples (Table 5). The maximum values of FBH detected for each experimental test are reported in Table 5 with the percentage of coarse structure.

\subsection{FEM campaign results}

$Q$ and $\varepsilon_{e q}$ are the mechanical indexes correlated with void closure phenomenon investigated in this study. Consequently, $Q$ and $\varepsilon_{e q}$ values were evaluated for each simulation along the longitudinal axis where shrinkage voids are mostly concentrated, and the detected values are almost constant along this zone of interest. Only in the entrance and exit zones of the workpiece the values were different since in rolling

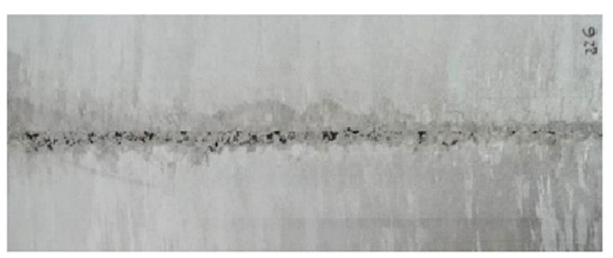

a)

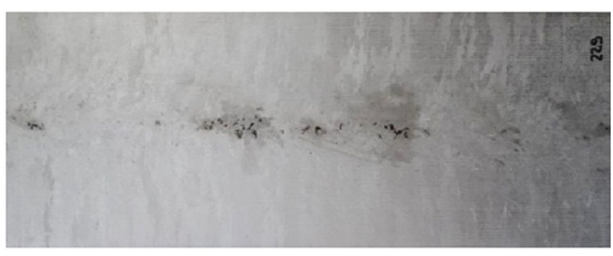

b)
Fig. 5. a) Experimental continuum voids distribution along longitudinal axis. b) Experimental isolated voids distribution along longitudinal axis. 
Table 5

Experimental US results.

\begin{tabular}{|c|c|c|c|c|c|c|c|c|c|c|c|c|}
\hline Test & AS1 & BS1 & AS2 & BS2 & AS3 & BS3 & AL1 & BL1 & AL2 & BL2 & AL3 & BL3 \\
\hline Coarse structure \% & 20 & 20 & 10 & 10 & 10 & $5-10$ & 30 & 20 & 10 & $5-10$ & 10 & 5 \\
\hline FBH range $[\mathrm{mm}]$ & $8 \pm 1$ & $9 \pm 1$ & $5.5 \pm 0.5$ & $7 \pm 1$ & $0 \pm 0.5$ & $5.5 \pm 1$ & $10 \pm 1$ & $10 \pm 1$ & $5.5 \pm 1$ & $7 \pm 1$ & $0 \pm 0.5$ & $4.5 \pm 0.5$ \\
\hline Morphology & $\mathrm{C}$ & $\mathrm{C}$ & I & I & I & I & $\mathrm{C}$ & $\mathrm{C}$ & I & I & I & I \\
\hline
\end{tabular}

$* \mathrm{C}=$ continuum; $\mathrm{I}=$ isolated.

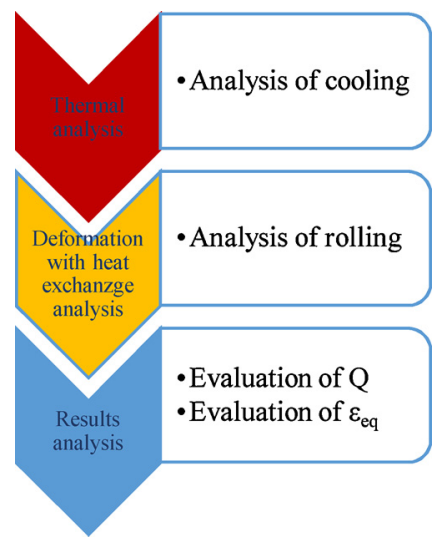

Fig. 6. The adopted procedure of FEA.

process these zones are subjected to different deformations with respect to the central workpiece part. Therefore, these zones were not considered in the analysis. Fig. 6 shows the simulation procedure.

Fig. 7 shows the FEA predicted thermal gradient through the transversal sample section after a cooling time of $270 \mathrm{~s}$ (Fig. 7a) and after $180 \mathrm{~s}$ (Fig. 7b). In Fig. 7c it is possible to see a plot of the temperature distribution between the workpiece along the workpiece section (black lines called distance in Fig. $7 \mathrm{a}$ and b). As expected, the thermal gradient between skin and core was heavier in the case of higher cooling time.

Figs. 8 and 9 show the FEM outputs as a function of the investigated parameters (i.e. thermal gradient; percentage of reduction; side of reduction). The values of $Q$ and $\varepsilon_{e q}$ were evaluated in the zone mostly affected by voids, in other words, along the sample longitudinal axis. Results for each test are summarized in Table 6. It is important to highlight that $Q$ parameter is negative (see Eqs. (1) and (2)). As a consequence, higher negative values of $Q$ indicate higher compressive stress state therefore higher void closure probability.

\subsection{Results discussion}

The US analysis results reported in Table 5 show that, fixed the side of reduction, maximum FBH values decreases as percentage reduction

a)

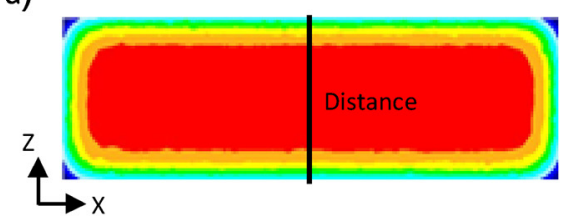

b)

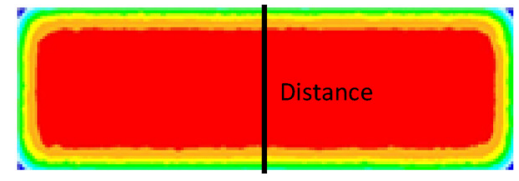

$1250^{\circ} \mathrm{C}$

$900^{\circ} \mathrm{C}$ or cooling time increase. This can be explained from the results reported in Table 6. In fact, at fixed cooling time, increasing percentage of pass reduction brings to higher compressive state (i.e., lower values of $Q)$ and higher deformation (i.e., higher values of $\varepsilon_{e q}$ ) at the workpiece core. Similarly, fixed percentage reduction, increasing the cooling time brings to higher compressive state $(Q)$ and higher deformation $\left(\varepsilon_{e q}\right)$ at the workpiece core. This behavior is in agreement with literature observations for AISI 52100 reported in the study of Llanos et al. (2008).

In particular, Fig. 10 plots the FEM results of $Q$ showing that, fixed percentage reduction and cooling time, when performing rolling on the short side (i.e., $280 \mathrm{~mm}$ ), bring to more negative values of $\mathrm{Q}$ than reductions on the long side (i.e., $340 \mathrm{~mm}$ ). In Fig. 10 the first number in the legend refers to the side of reduction while the second number refers to cooling time (i.e. Q 280180 refers to the values of $Q$ of the rolling tests performed on the shorter side with a cooling time of $180 \mathrm{~s}$ ). x Figs. 11, 12 and 13.

The correlation between experimental residual porosity (i.e. FBH) and FEA predicted $Q$ value, is reported in Fig. 11. It can be seen that, when fixed the side of reduction, the lower is $Q$ the lower are the residual FBH values.

Regarding to $\varepsilon_{e q}$, Fig. 12 plots the FEA results, showing that, fixed percentage reduction and cooling time, when performing rolling on the long side (i.e., $340 \mathrm{~mm}$ ) brings to higher values of $\varepsilon_{e q}$ than the reduction on the short side (i.e., $280 \mathrm{~mm}$ ).

The correlation between experimental residual porosity (i.e., FBH) and FEM predicted $\varepsilon_{e q}$ value, is reported in Fig. 13. It can be seen that, fixing the side of reduction, the higher is $\varepsilon_{\text {eq }}$, the lower is the percentage of residual porosity detected.

Summarizing the obtained results, it can be seen that, at fixed percentage of reduction and cooling time, reducing on the short side brings to lower values of $Q$ but also to lower values of $\varepsilon_{e q}$, while reducing on the long side brings to higher values of $\varepsilon_{e q}$ but also to higher values of $Q$.

Since at fixed process parameters (percentage of reduction and cooling time, see Table 5) final FBH values were similar for the two sides, both the $Q$ parameter and $\varepsilon_{e q}$ should be taken in account as drivers of void closure evolution. This finding is in agreement with the models proposed in literature.

Analysing the literature there is an interest for defining rolling geometrical factors linked to void closure. An intuitive example can be the percentage of reduction, as suggested by Stahlberg et al. (1980).

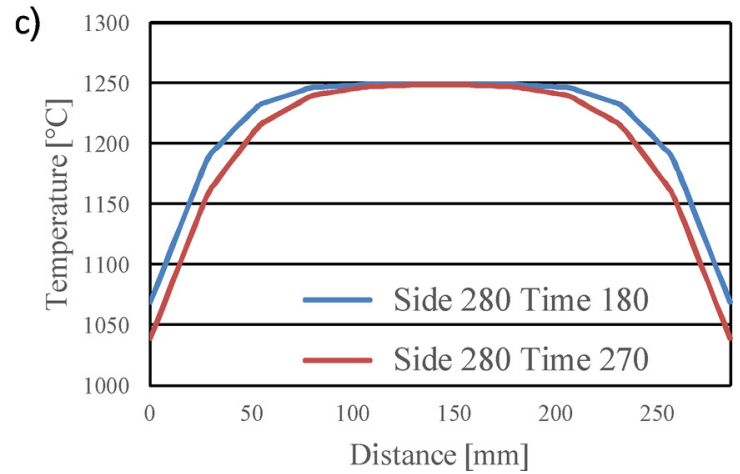

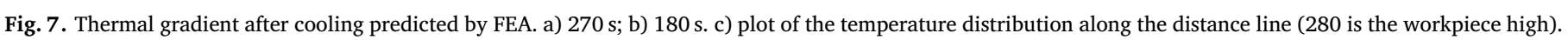




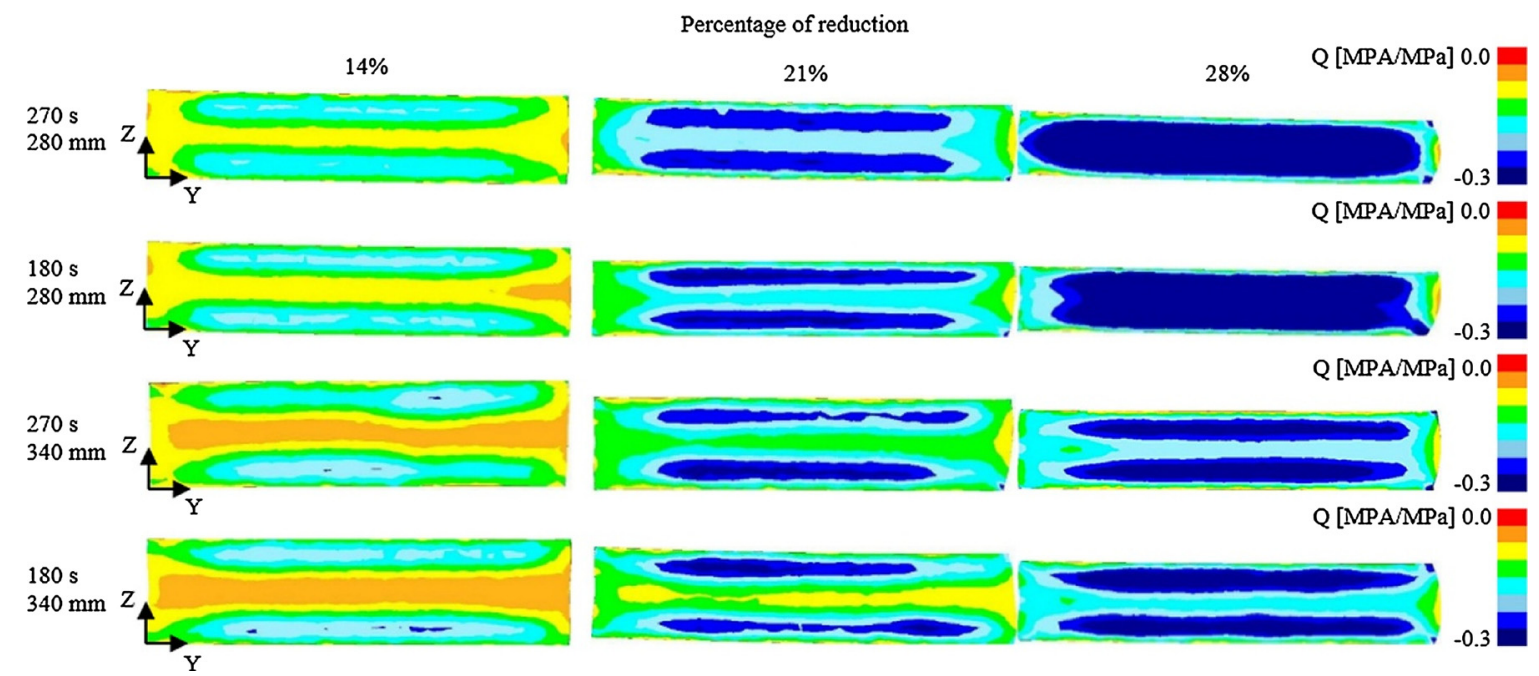

Fig. 8. Value of $\mathrm{Q}$ predicted by FEA for each test $[\mathrm{MPa} / \mathrm{MPa}]$.

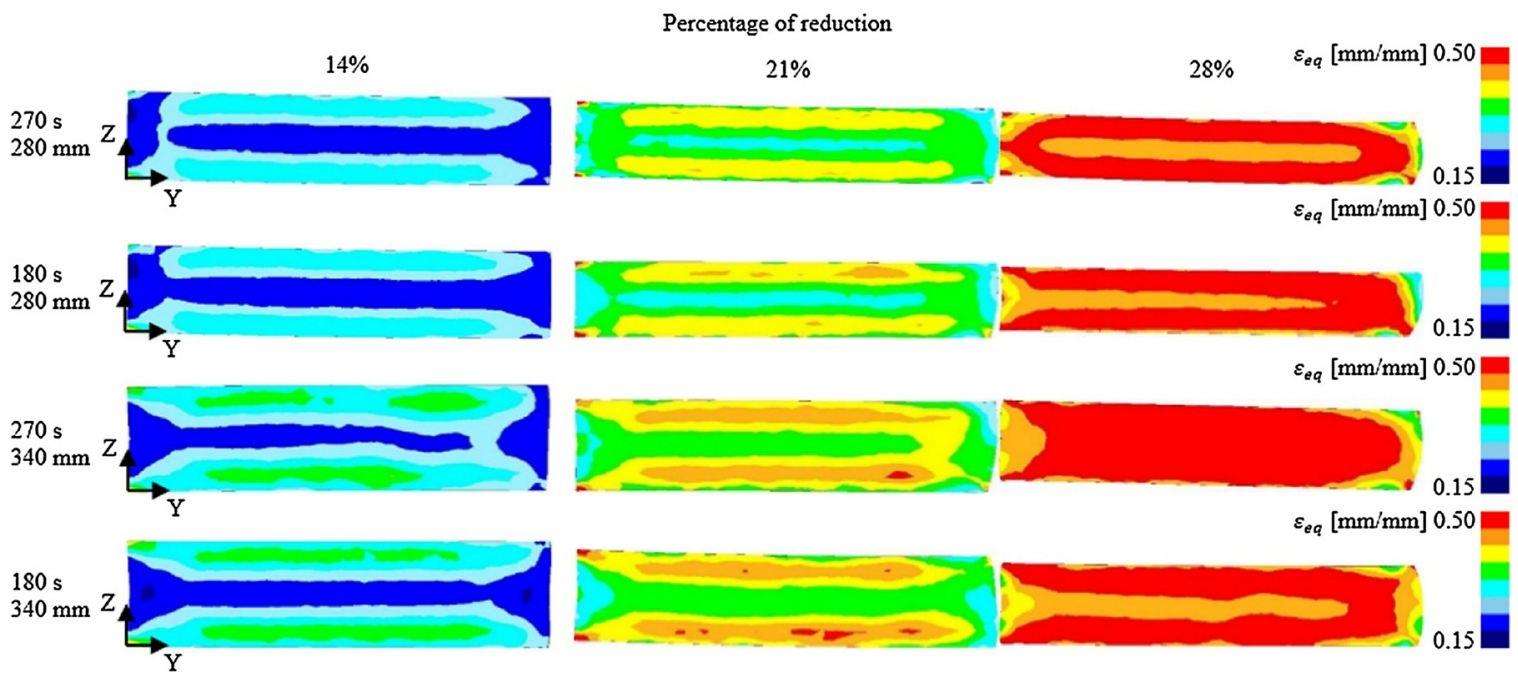

Fig. 9. Value of $\varepsilon_{\text {eq }}$ predicted by FEA for each test $[\mathrm{mm} / \mathrm{mm}]$.

Table 6

FEM Q and $\varepsilon_{e q}$ values predicted by FEA in the zone of the shrinkage porosity (longitudinal axis).

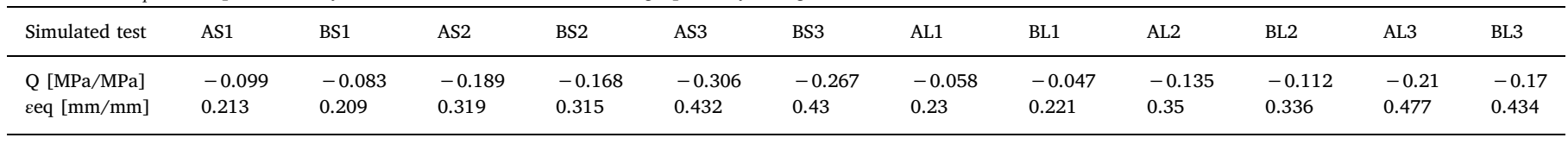

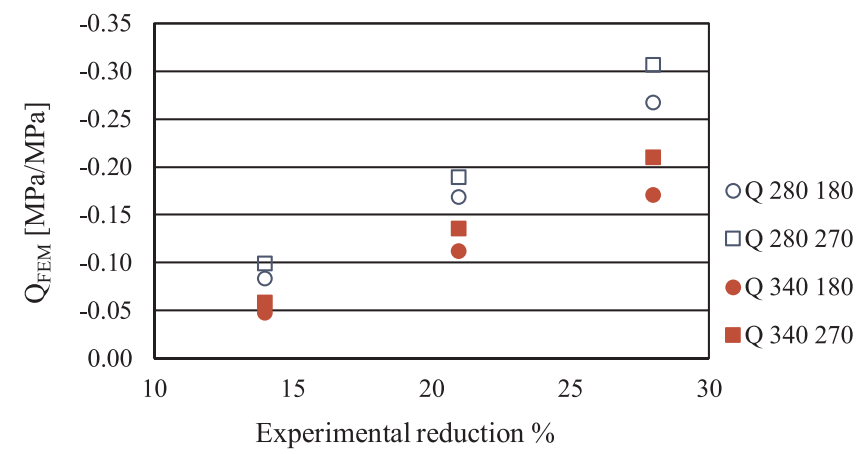

Fig. 10. Correlation between the $Q$ parameter predicted by FEA and the percentage of reduction.

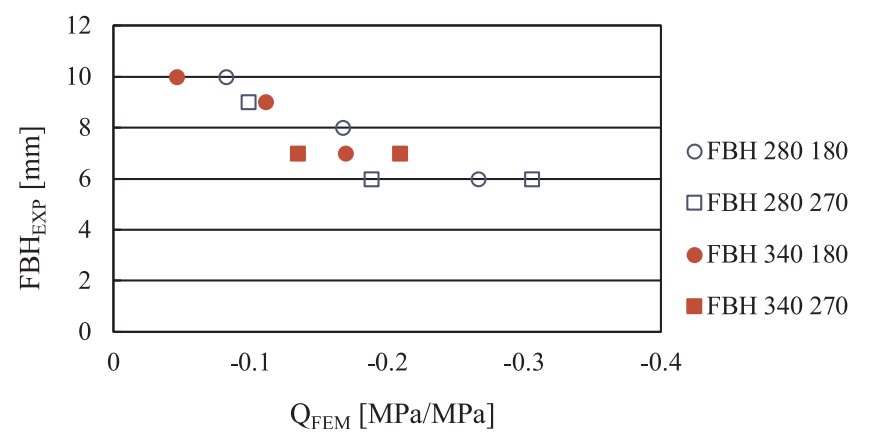

Fig. 11. Correlation between the $Q$ parameter predicted by FEA and the experimental measure of residual porosity. 


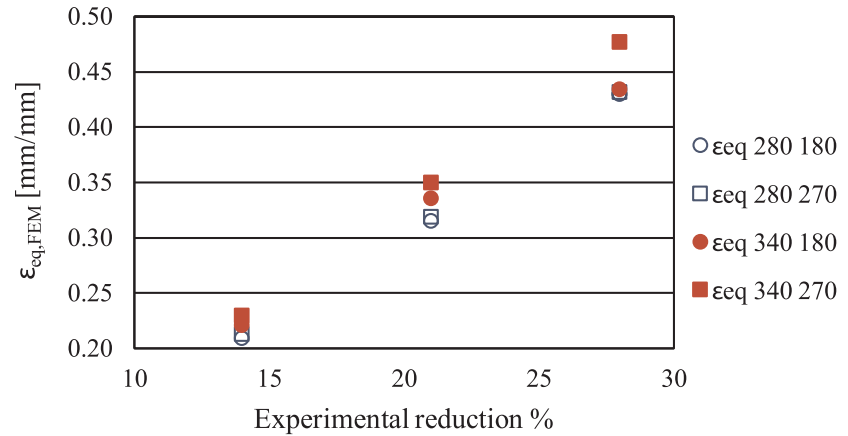

Fig. 12. Correlation between $\varepsilon_{\text {eq }}$ predicted by FEA and the percentage of reduction.

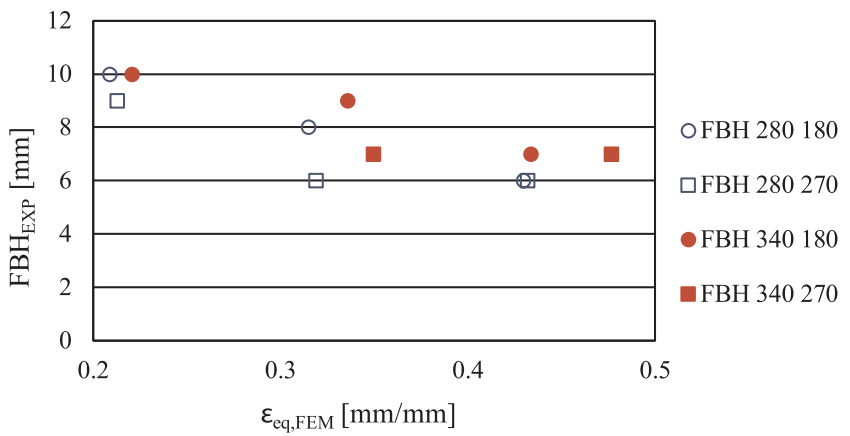

Fig. 13. Correlation between $\varepsilon_{\text {eq }}$ predicted by FEA and the experimental measure of residual porosity.

Farrugia, 2016 proposed another factor, here called $G_{1}$, defined as the ratio between the mean height of workpiece $h_{m}$ and the contact length $L$ (see Fig. 14). The mean height $h_{m}$ can be calculated from the initial height of the billet $h_{1}$ and the final $h_{2}$ by using Eq. (6). The contact length can be calculated from $h_{1}, h_{2}$ and the roll radius $R$ (Eq. (7)).

$h_{m}=\frac{h_{1}+h_{2}}{2}$

$L=\sqrt{R^{2}-\left(R-\frac{h_{1}-h_{2}}{2}\right)^{2}} \approx \sqrt{R \cdot\left(h_{1}-h_{2}\right)}$

Then expression of $G_{1}$ is provided by Eq. (8), where lower values of $G_{1}$ are associated with higher reduction values, useful from a void

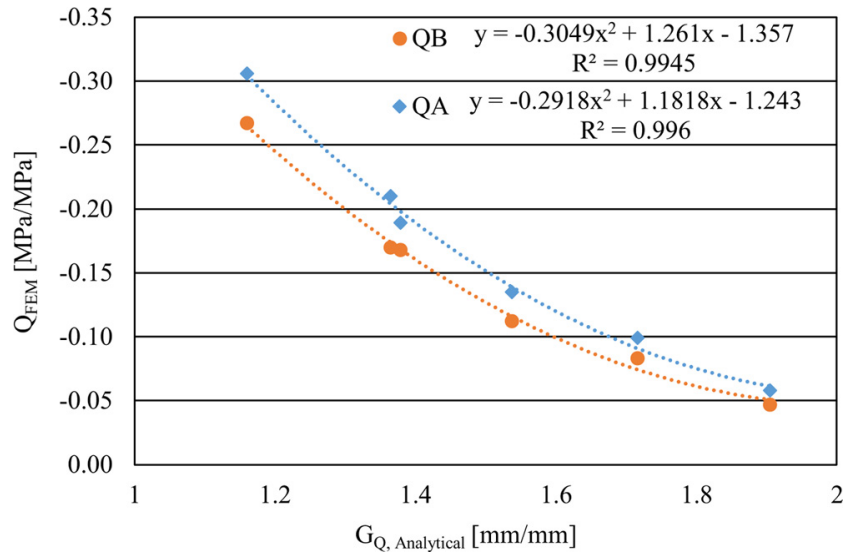

Fig. 15. Correlation between $\varepsilon_{\text {eq }}$ predicted by FEA and the geometrical index $\mathrm{G}_{\mathrm{Q}}$.

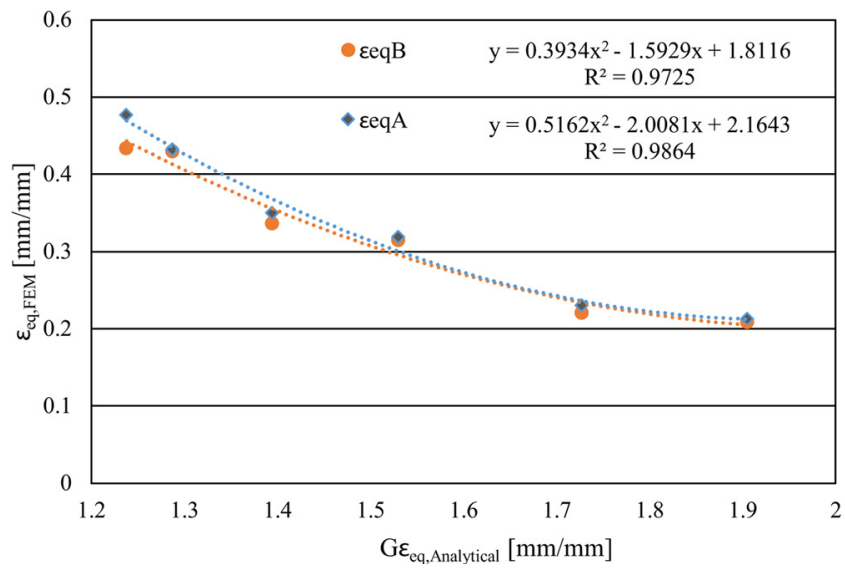

Fig. 16. Correlation between $\varepsilon_{\text {eq }}$ predicted by FEA and the geometrical index $\mathrm{G}_{\varepsilon \mathrm{eq}}$.

closure point of view. In the study of Farrugia, $2016 G_{1}$ was related to the stress state in the workpiece by means of 2D FEM simulations.

$G_{1}=\frac{h_{m}}{L}$

From Eq. (8) it can also be seen that $G_{1}$ does not take into account

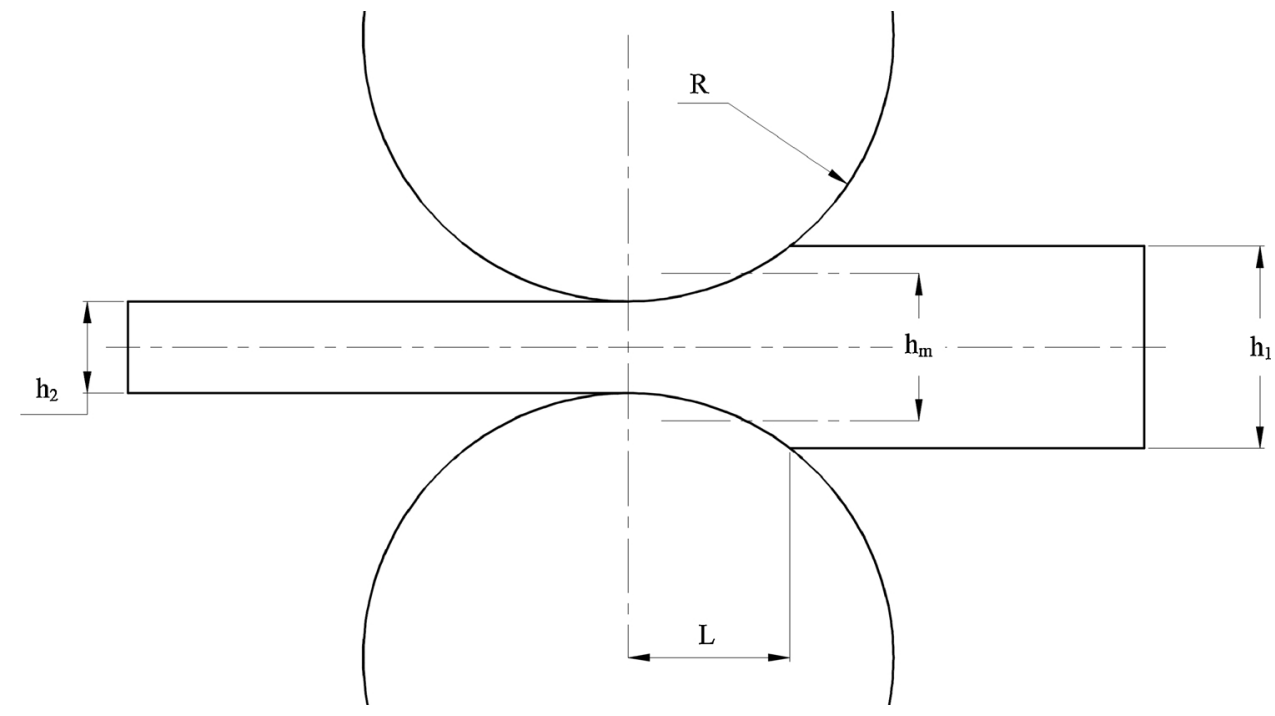

Fig. 14. Draw of the arc contact. It is possible to see the contact length $L$ and the mean height $h_{m}$. 
any information about the transversal side of the workpiece where spread occurs.

The results of our investigations described above and resumed in Figs. 11 and 13, show that workpiece orientation plays an important role, therefore factors as percentage of reduction or $G_{1}$ are not sufficient to take into account both the effect of the rolling geometry (i.e., reduction imposed and rolls radius) and workpiece orientation (i.e., the side on which reduction is performed and the transversal side in which spread occurs) on the mechanical void closure indexes, $Q$ and $\varepsilon_{e q}$.

For this reason, a new single rolling geometrical $G$ factor should be defined considering reduction, side of reduction and transversal side. If possible, this $G$ factor should be related to $Q$ and $\varepsilon_{e q}$. In this study, $G$ was defined as a function of $G_{1}$ and of another second geometrical factor here introduced and called $G_{2}$. In particular, the second factor $G_{2}$, should mainly take into account the orientation of the workpiece in the mill. As a consequence, it can be simply defined as the ratio between the side of reduction $h_{1}$ and the other side $w_{1}$ which is in contact with the rolls (Eq. (9)). In this way, the lower is $h_{1}$, the lower is $G_{2}$. At the same time, the higher is $w_{1}$, the lower is $G_{2}$. Note that if $G_{2}$ comes closer to zero, we have a physical situation closer to a plain strain condition.

$G_{2}=\frac{h_{1}}{w_{1}}$

The final geometrical $G$ factor is a function of $G_{1}$ and $G_{2}$ as shown in Eq. (10).

$G=f\left(G_{1}, G_{2}\right)$

In this study, it was found that Eq. (11) gives a suitable mathematical form of the geometrical $\mathrm{G}$ factor for obtaining the best fitting of $\mathrm{Q}$ data $\left(R^{2}=0.9945\right.$ for tests with cooling time of $270 s$ and $R^{2}=0.996$ for tests with cooling time of $180 \mathrm{~s}$ ).

$G_{Q}=\frac{1}{2} \cdot G_{1} \cdot\left[1+G_{2}^{\left|\ln G_{2}\right|}\right]$

From Eqs. (8), (9) and (11), when increasing pass reduction or length of contact and reducing on short side it brings to lower $\mathrm{G}_{\mathrm{Q}}$ value. Fig. 15 shows the fitting for the tests with cooling time of $270 \mathrm{~s}$ and tests with cooling time of $180 \mathrm{~s}$. It can be seen that the lower is the geometrical index $G_{Q}$ the lower is the value of $\mathrm{Q}$.

Likewise, it was found that Eq. (12) gives a suitable mathematical form of the geometrical $\mathrm{G}$ factor for the fitting of $\varepsilon_{e q}$ data $\left(\mathrm{R}^{2}=0.9725\right.$ for tests with cooling time of $180 \mathrm{~s}$ and $\mathrm{R}^{2}=0.9864$ for tests with cooling time of $270 \mathrm{~s}$ ).

$G_{Q}=\frac{1}{2} \cdot G_{1} \cdot\left[1+G_{2}^{\left|l n G_{2}\right|-1}\right]$

From Eqs. (8), (9) and (12) it was found that, increasing pass reduction or length of contact and reducing on long side brings to lower value of $\mathrm{G}_{\varepsilon e q}$. Fig. 16 shows the fitting for both tests with cooling time of $270 \mathrm{~s}$ and tests with cooling time of $180 \mathrm{~s}$. It can be seen that the lower is the geometrical index $\mathrm{G}_{\varepsilon e q}$ the higher is the value of equivalent strain.

\section{Conclusions}

This paper reports the most important findings related with a study on the effects of rolling process parameters on void closure of continuous casting slabs made of AISI $316 \mathrm{~L}$ stainless steel.

The residual voids after hot rolling forming process were experimentally evaluated through US non-destructive controls in terms of equivalent flat bottom hole (FBH). Finite element simulations of the experimental tests were performed in order to analyse the effect of two mechanical indexes $\left(Q\right.$ and $\left.\varepsilon_{e q}\right)$ on void closure. A correlation between these indexes and the equivalent void diameter $(\mathrm{FBH})$ was identified for AISI 316L stainless steel, showing that these indexes are representatives of the void crushing. Furthermore, the FE analysis allowed to study the influence of the process parameters on $Q$ and $\varepsilon_{e q}$. In particular, fixed the side of reduction, the higher the percentage of reduction and the cooling time, the lower is the value of $Q$ and the higher is the $\varepsilon_{e q}$. This results in higher probability of closing the material internal defects. In fact, low $Q$ values and high $\varepsilon_{e q}$ values are respectively associated to high compressive state and high deformation in the material. Concerning the influence of the side of reduction on the indexes, it was observed that reducing the billet height along the shorter side results in higher values of $Q$ and lower values of $\varepsilon_{e q}$. On the contrary, to reduce the billet along the longer side generates lower values of $Q$ and higher values of $\varepsilon_{\text {eq }}$. As for standard steel also for AISI 316L stainless steel it is possible to conclude that the final part quality improves setting high pass reduction and increasing the thermal gradient between core and skin.

Finally, two geometrical indexes $\left(G_{Q}\right.$ and $\left.G \varepsilon_{e q}\right)$ related to $Q$ and $\varepsilon_{e q}$ indexes were defined and their limits were analysed. These geometrical indexes, derived from the rolling process parameters, describe the variation of $Q$ and $\varepsilon_{e q}$ and, as a consequence, can be used to find the best process set-up minimising the internal voids of the billet.

\section{Acknowledgement}

The authors would like to gratefully thank Cogne Acciai Speciali S.p.a. industries for funding an support this research.

\section{References}

Banaszek, G., Stefanik, A., 2006. Theoretical and laboratory modelling of the closure of me tallurgical defects during forming of a forging. J. Mater. Process. Technol. 177 (1), 238-242. http://dx.doi.org/10.1016/j.jmatprotec.2006.04.023.

Chbihi, A., Bouchard, P.-O., Bernacki, M., Pino Muñoz, D., 2017. Influence of lode angle on modelling of void closure in hot metal forming processes. Finite Elem. Anal. Des. 126 (C), 13-25. http://dx.doi.org/10.1016/j.finel.2016.11.008.

Chen, D.C., 2006. Rigid-plastic finite element analysis of plastic deformation of porous metal sheets containing internal void defects. J. Mater. Process. Technol. 180 (1), 193-200. http://dx.doi.org/10.1016/j.jmatprotec.2006.06.004.

Chen, J., Chandrashekhara, K., Mahimkar, C., Lekakh, S.N., Richards, V.L., 2011. Void closure prediction in cold rolling using finite element analysis and neural network. J. Mater. Process. Technol. 211 (2), 245-255. http://dx.doi.org/10.1016/j.jmatprotec.2010.09.016.

Chen, M.S., Lin, Y., 2013. Numerical simulation and experimental verification of void evolution inside large forgings during hot working. Int. J. Plast. 49, 53-70. http://dx.doi.org/10. 1016/j.ijplas.2013.02.017.

Farrugia, D., 2016. Modelling central consolidation during hot rolling of cast products. Key Eng. Mater. 716, 728-735. http://dx.doi.org/10.4028/www.scientific.net/KEM.716.728.

Hensel, A., Spittel, T., 1986. Kraft- und Arbeitsbedarf bildsamer Formgebungsverfahren. VEB Deutscher Verlag für Grundstoffindustrie, Leipzig.

Hwang, Y.M., Chen, D.C., 2003. Finite element simulations on void closure behavior inside the sheet during sheet rolling processes. Proc. Inst. Mech. Eng. Part B J. Eng. Manuf. 216 (9), 1227-1237. http://dx.doi.org/10.1243/095440502760291781.

Kakimoto, H., Arikawa, T., Takahashi, Y., Tanaka, T., Imaida, Y., 2010. Development of forging process design to close internal voids. J. Mater. Process. Technol. 210 (3), 415-422. http:/ dx.doi.org/10.1016/j.jmatprotec.2009.09.022.

Kang, S.H., Kim, S.W., Lee, Y.S., 2010. Application of modified hydrostatic stress model to internal void crushing in forging of large-scale ingot. Steel Res. Int. (81), 9.

Llanos, J.M., Santisteban, V., Demurger, J., Kieber, B., Forrestier, R., Rogberg, B., De Santis, M., Lundbäck, H., 2008. Improvement of central soundness in long products from a through process control of solidification and reheating and rolling parameters. Tech. Rep. Eur. Comm. Res. Fund Coal Steel 149. http://dx.doi.org/10.2777/12946.

Nakasaki, M., Takasu, I., Utsunomiya, H., 2006. Application of hydrostatic integration parameter for free-forging and rolling. J. Mater. Process. Technol. 177 (1-3), 521-524. http:// dx.doi.org/10.1016/j.jmatprotec.2006.04.102.

Saby, M., Bernacki, M., Roux, E., Bouchard, P.-O., 2013. Three-dimensional analysis of real void closure at the meso-scale during hot metal forming processes. Comput. Mater. Sci. 77, 194-201. http://dx.doi.org/10.1016/j.commatsci.2013.05.002.

Saby, M., Bouchard, P.-O., Bernacki, M., 2015a. Void closure criteria for hot metal forming: a review. J. Manuf. Process. 19, 239-250. http://dx.doi.org/10.1016/j.jmapro.2014.05.006.

Saby, M., Bouchard, P.-O., Bernacki, M., 2015b. A geometry-dependent model for void closure in hot metal forming processes. Finite Elem. Anal. Des. 105 (C), 63-78. http://dx.doi.org/ 10.1016/j.finel.2015.07.003.

Stahlberg, U., Keife, H., Lundberg, M., Melander, A., 1980. A study of void closure during plastic deformation. J. Mech. Work. Technol. 4 (1), 51-63. http://dx.doi.org/10.1016/ 0378-3804(80)90005-4.

Stahlberg, U., 1986. Influence of spread and stress on the closure of a central longitudinal hole in the hot rolling of steel. J. Mech. Work. Technol. 13 (1), 65-81. http://dx.doi.org/10. 1016/0378-3804(86)90043-4.

Stahlberg, U., Keife, H., 1992. A study of hole closure in hot rolling as influenced by forced cooling. J. Mater. Process. Technol. 30 (1), 131-135. http://dx.doi.org/10.1016/09240136(92)90043-R.

Tanaka, M., Ono, S., Tsuneno, M., 1986. Factors contributing to crushing of voids during forging. J. Jpn. Soc. Technol. Plast. 27 (306), 927-934.

Wallerö, A., 1985. Closing of a central longitudinal pore in hot rolling. J. Mech. Work. Technol. 12 (2), 233-242. http://dx.doi.org/10.1016/0378-3804(85)90138-X. 